\title{
La rencontre entre la culture marocaine et la culture française et son impact sur le conte populaire marocain
}

\author{
FARAH ABDELALI \\ Université Hassan II de Casablanca / Maroc \\ $凶$ Farah.abdelali@gmail.com
}

RÉSUMÉ. Cet article étudie les traits d'une hybridité culturelle, relevés lors de la présentation d'un conte marocain revisité, dans le cadre d'un festival international du conte organisé en France. Nous montrons dans la première partie que, pour répondre aux exigences de cette notion, le conteur a eu recours à des symboles reconnaissables par le public et à d'autres traits qui ont un sens presque similaire dans sa culture d'origine et dans celle du pays d'accueil. La seconde partie montre que tout comme le texte, les gestes, le costume, la gestion de l'espace et même la durée du conte ont été soumis à la particularité de ce contexte interculturel. Dans

MOTS CLÉS:

Conte ;

interculturalité ;

hybridité culturelle ; performance orale ; réécriture la dernière partie, nous soulignons que malgré les efforts fournis par le conteur pour construire un pont entre sa culture et celle de son public, des contraintes linguistiques et sémantiques s'imposent au moment de la narration.

\section{Pour citer cet article}

Abdelali, F. (2021). La rencontre entre la culture marocaine et la culture française et son impact sur le conte populaire marocain. Hybrida, (2), 57-79. https://doi.org/10.7203/ HYBRIDA.2.20652 
RESUMEN. El encuentro entre la cultura marroquí y la cultura francesa y su impacto en el cuento popular marroquí. Este artículo estudia los rasgos de hibridación cultural que se observaron durante la presentación de un cuento marroquí adaptado al marco de un festival internacional de cuentos organizado en Francia. En la primera parte mostramos que, para cumplir los requisitos de esta noción, el narrador recurrió a símbolos que el público reconoció y a otros rasgos que tienen un significado casi similar en la cultura original y en la del país de acogida. La segunda parte muestra que al igual que el texto, los gestos, el vestuario, la gestión del espacio e incluso la duración del relato estaban sometidos a la particularidad de este contexto intercultural. En la última parte, destacamos que, a pesar de los esfuerzos realizados por el narrador para tender un puente entre su cultura y la del público, durante la narración se imponen limitaciones lingüísticas y semánticas.

ABSTRACT. The encounter between Moroccan and French culture and its impact on the Moroccan folk tale. This article studies the features of a cultural hybridity, noted during the presentation of a Moroccan tale revisited, within the framework of an international festival of tale, organized in France. We show in the first part that in order to meet the requirements of this notion, the storyteller used symbols recognizable by the audience and other features that have an almost similar meaning in his original culture and in that of the host country. The second part shows that just like the text, the gestures, the costume, the management of the space and even the duration of the tale were subjected to the particularity of this intercultural context. In the last part, we describe that in spite of the efforts made by the storyteller to build a bridge between his culture and that of his audience, linguistic and semantic constraints are imposed at the time of the narration.
PALABRAS CLAVE:

\section{Cuento;}

interculturalidad;

hibridación

cultural; interpretación oral; reescritura

KEYWORDS:

Storytelling; interculturality; cultural hybridity; oral performance; rewriting 


\section{Introduction}

En quittant son pays ainsi que la sphère dans laquelle il avait l'habitude de conter, le conteur populaire marocain est amené à retravailler sa langue, ses codes ainsi que l'ensemble des représentations qu'il a acquis au sein de sa communauté, afin de réussir sa performance orale. Au-delà d'une simple situation de communication où le conteur échange avec son public, la performance orale est une représentation microscopique des rituels et des comportements sociaux qui peuvent être considérés dans la vie quotidienne comme négligeables, voire anodins. Deborah A. Kapchan apporte un éclairage dans ce sens :

Ces performances offrent un contrepoint complexe aux pratiques inconscientes de la vie quotidienne dans la mesure où elles représentent des expressions de l'altérité marquées sur le plan stylistique, rehaussant le niveau des comportements habituels et entrant dans un cadre interprétatif alternatif, souvent ritualisé ou ludique, où des règles différentes s'appliquent. (Kapchan, 2017, p. 21)

En juillet 2016, j’ai mené une enquête de terrain dans trois villes du Maroc, Fès, Meknès et Marrakech, en vue de collecter des contes marocains traditionnels et revisités. Le conteur que j'ai rencontré sur la place Jemaa el-Fna à Marrakech était un quinquagénaire et un professionnel des cercles de contes. Il a quitté l'école à un âge précoce et a travaillé avec un homme de nationalité française qui lui a permis d'apprendre sa langue. Chaque fin de journée, et après de longues heures de travail, il se rendait à la place Jemaa el-Fna pour assister aux performances orales, animées par les conteurs de l'époque. C'est ainsi qu'il fut impressionné par cet art et qu'il a décidé d'en faire son métier.

J'ai rencontré le conteur avant qu'il ne commence son spectacle, pour recueillir son témoignage concernant la différence entre les contes traditionnels et les contes revisités, dits détournés. C'est ainsi qu'il m’a fait découvrir que parfois certains contes, issus du patrimoine oral marocain, peuvent faire l'objet d'une modification afin de s'adapter à de nouveaux contextes culturels. Afin d'illustrer ses propos, il a évoqué son expérience dans le cadre d'un festival de conte en France auquel il a été invité pour présenter un conte marocain. Pour ce faire, il a choisi de s'inspirer du conte Aicha Rmada afin de proposer une nouvelle version intitulée La fille de la lune, qui portera la marque de son identité mais qui sera plus adaptée à l'imaginaire du pays d'accueil.

Tout d'abord, il m'a proposé d'assister à son spectacle dans lequel il allait conter Aicha Rmada en arabe, que j'ai moi-même traduit par la suite en langue française. Il s'est fait entourer par des marocains, habitués de la Halqa, mais aussi par des touristes de nationalités différentes qui étaient curieux de découvrir le sens de ces 
paroles incompréhensibles qui charmaient le public. À la clôture de la Halqa, le conteur m'a livré le second récit qu'il a conté en France, intitulé La flle de la lune.

Le recueil de ces deux versions s'est fait sous forme d'une prise de notes, puisque j’ai été incapable de les enregistrer à cause du vacarme qui caractérisait la place. Par la suite, le conteur m'a décrit les contraintes qu'il a rencontrées afin de proposer un conte en langue française, qui porte la marque de sa propre identité ainsi que celle du public français. Nonobstant ces obstacles, il est parvenu à réussir sa performance. En effet, ce fut grâce aux informations retenues lors des échanges qu'il a eus avec des conteurs français qu'il côtoyait lorsqu'ils visitaient le Maroc ou qu'il rencontrait dans le cadre des ateliers ou des festivals de contes. Mon interlocuteur a mis l'accent sur l'intérêt de ces rencontres qui lui ont permis d'une part d'apprendre les différences entre sa propre culture et celle de la société française et d'autre part, de découvrir certains symboles propres à l'imaginaire de cette dernière.

Pour cette raison et en plus de son propre bagage culturel, le conteur s'inspire des modes et des moyens de communication utilisés dans la société française ainsi que du référent culturel de ce pays afin de mettre en place un code de communication hybride. La notion d'hybridité culturelle est utilisée dans cet article dans le sens qui lui a été attribuée par John Hutnyk et traduit par Marion Sauvaire ${ }^{1}$ : « L'hybridité apparaît comme une catégorie commode à la lisière ou au point de contact de la diaspora, décrivant le mélange culturel là où la personne issue de la diaspora rencontre l'hôte, sur la scène de la migration. » (Hutnyk, 2005, p. 79)

Pour mieux rendre compte des enjeux rencontrés par le conteur lors de la présentation de sa performance dans un pays d'accueil, il convient de rappeler qu'au Maroc, l'art de conter est une tradition héritée des anciens conteurs des places publiques, qui a influencé plusieurs amateurs ou professionnels de ce genre. Ladite tradition repose essentiellement sur la parfaite symbiose entre deux pôles qui partagent le même référent culturel, religieux et linguistique, à savoir le conteur et le public. À cet effet, cette performance cesse d'être un simple moment de divertissement et prend plutôt la forme d'un regroupement d'individus, basé sur des critères identitaires.

Or dans un pays d'accueil, le conteur doit prendre conscience des différences entre sa propre identité et celle du public, et mettre en scène un conte revisité où il reprend certains symboles et codes propres à la culture de ses interlocuteurs. Dans le cas contraire, et si le conteur se contente de raconter fidèlement le conte traditionnel, puisé dans le patrimoine oral marocain, il prendra le risque de se retrouver, une fois sur scène,

1 L'article de Marion Sauvaire sera cité dans les références bibliographiques. 
en position de fragilité. De cette manière, il sera incapable de captiver l'attention du public. Cela est dû au fait que certains symboles reçoivent des interprétations différentes dans chaque culture du monde. Par conséquent, cela peut affecter le sens du récit et entraver sa compréhension. Dans cet ordre d'idée, Roland Hubert et Stéphanie Vanasten témoignent de «La nécessité d'adapter l'histoire et le genre à cet autre contexte socio-culturel et discursif. »(Hubert et Vanasten, 2010, p. 36)

À travers ces propos, Roland Hubert et Stéphanie Vanasten expliquent que dans un pays d'accueil, le conteur est amené à adapter la version populaire de son conte, en guise de reconnaissance et d'acceptation de l'autre, à un sujet différent qui a ses propres spécificités linguistiques et socio-culturelles. Dans ce sens, les modifications apportées à la version traditionnelle du conte marocain contribuent à installer un espace d'échange où se rencontrent deux cultures hétérogènes, à savoir, les cultures marocaine et française qui s'apprêtent à communiquer et à s'accepter mutuellement.

En effet, on ne peut analyser cette situation de communication sans évoquer la notion d'interculturalité. Afin de l'élucider, nous proposons de considérer les propos de Pierre Roques Dasen et de Jean Retschitzki :

On peut distinguer deux approches complémentaires dans la recherche interculturelle. Premièrement, l'étude de la diversité culturelle, avec ou sans comparaison explicite entre les cultures, permet de mieux comprendre l'ensemble des sociétés humaines, et par le miroir de l'altérité, de mieux comprendre sa propre société. Dans les sciences humaines, une méthode comparative permet de remettre en question des théories établies dans un contexte particulier, mais trop souvent considérées a priori comme universelles. D'autre part, dans le monde actuel, les contacts entre groupes culturels se multiplient, dans des situations et pour des raisons fort diverses. Une grande partie de la recherche interculturelle porte sur l'ensemble des phénomènes liés à ces contacts. (Dasen et Retschitzki, 1989, pp. 9-16)

De son côté, Christophe Clanet ajoute que la notion d'interculturalité est conditionnée par des «changements » et "des transformations " qui doivent survenir sur les individus appartenant à des cultures différentes lorsqu'ils « entrent en contact ». (Clanet, 1993, p. 22). C'est une notion qui peut être évoquée pour expliquer la coexistence de plusieurs aspects identitaires propres à des communautés différentes $\mathrm{du}$ monde qui se rencontrent dans un espace commun.

À la lumière des conceptions de Dasen, de Retschitzki et de C. Clanet, nous pouvons considérer que « la scène de migration ${ }^{2}$ est l'un des contextes dans lequel les

2 Nous empruntons l'expression de John Hutnyk citée au préalable. 
individus découvrent l'altérité ainsi que les différentes identités composant le monde. De ce contexte résulte nécessairement la communication interculturelle. Elle est le fruit d'une interaction entre deux ou plusieurs individus qui ne partagent pas les mêmes codes, valeurs et croyances mais qui œuvrent pour créer un terrain d'entente où ils peuvent se comprendre et échanger. Bo Shan apporte un éclairage dans ce sens :

La communication interculturelle est constituée par l'interaction de l'homme dans le contexte des cultures différentes [...] Quand un individu est intégré dans un groupe, il a l'obligation d'abandonner une certaine individualité pour demeurer et se mettre en accord avec la norme du groupe, afin que le partage des valeurs soit réalisé et qu'un certain système de valeur culturelle soit formé. (Shan, 2004).

En effet, la communication interculturelle permet au conteur de constater et de relever les différences entre sa propre culture et celle de son public. À cet égard, il propose un conte revisité où ces deux cultures sont mises en connexion et qui se caractérise par une hybridité culturelle aussi bien sur le plan verbal que paraverbal. Ce conte est marqué par l'insertion de certains symboles propres à l'imaginaire et à la culture française, mais aussi par la représentation de quelques aspects propres à la culture originelle du conteur.

Dans cet article, nous interrogerons les moyens qui permettent au conteur populaire marocain d'adapter la version traditionnelle de son conte à un contexte interculturel. Nous nous demandons également comment se manifeste la notion d'hybridité culturelle dans ce conte revisité, et quelles sont les contraintes qui ont entravé la mise en scène de ladite notion, sachant que ce conteur est en interaction avec un modèle culturel différent du sien.

Même si la notion de communication interculturelle est de caractère bilatéral et qu'elle sollicite l'implication de tous les intervenants, dans cet article, nous n'allons étudier que les ouvrages mis en place par le conteur marocain pour persuader et pour entrer en contact avec le public français.

Afin de mettre en lumière ces éléments, nous allons comparer les composants du conte Ä̈cha Rmada [Aïcha souillée de Cendres] issu du patrimoine oral marocain avec La fille de la lune qui est la version revisitée du même conte, présentée dans le cadre d'un festival international du conte en France.

Dans un premier temps, il nous paraît important d'étudier les traits de la mise en œuvre d'une hybridation culturelle qui favorisera la coexistence de deux imaginaires différents et par conséquent la réussite de la performance orale du conteur dans un contexte interculturel. Nous allons étudier ensuite les changements survenus lors de la performance orale du conteur dans la scène de migration, puisque la séance de conte est composée non seulement du récit mais également d'un ensemble d'éléments non verbaux 
qui aident le récepteur à se représenter mentalement les idées transmises. En revanche, l'adaptation d'un conte traditionnel au dit contexte n'est pas un ouvrage facile, c'est pour cette raison qu'il sera essentiel de soulever dans la dernière partie les contraintes linguistiques et culturelles que rencontre le conteur pour produire cette nouvelle version.

Avant d'entamer notre étude, nous proposons en premier lieu de lire les transcriptions des deux contes Aïcha Rmada et La fille de la lune :

Aïcha Rmada :

Il y avait un homme âgé qui avait épousé deux femmes. L'une était douce, aimable et belle, l'autre était méchante, d'une laideur sans pareil, en plus, elle était sorcière.

Le destin fit que les deux épouses accouchèrent le même jour. La première mit au monde une fillette aussi belle que la lune qu'elle appela Aïcha, et la deuxième en enfanta une laide aussi affreuse qu'elle. Et depuis ce jour, la sorcière devint encore plus jalouse qu'elle ne l'était de la deuxième épouse.

Un jour, de retour de la rivière où elles avaient lavé la laine, les deux épouses s'aperçurent que l'âne qui les avait ramenées avait disparu. Alors la sorcière proposa à la belle de la transformer en vache puis en âne pour qu'elles puissent retourner à la maison avec la laine, et lui promit de la transformer ensuite de l'âne en vache, et de la vache à sa forme humaine.

Arrivées à la demeure, la méchante déchargea la laine et cria des formules étranges afin de transformer l'âne en vache et puis elle s'arrêta. Elle conduisit la vache à l'écurie, l'accrocha à un anneau profondément incrusté dans le mur et retourna seule à la maison. La vache se mit à beugler de toutes ses forces, mais en vain.

Quand le mari rentra le soir, il appela sa belle épouse. La méchante lui répondit : «Quand nous étions à la rivière elle s'est éloignée et elle n'est plus revenue. Par contre, Dieu nous a envoyé une vache que j'ai enfermée à l'écurie.»

Et l'homme oublia aussitôt sa femme!

À partir de ce jour, la laide s'emportait contre la petite fillette et lui faisait subir les mots les plus haïssables et les tâches les plus viles de la maison. Et pour l'humilier davantage, elle lui jetait chaque jour une poignée de cendres sur son visage angélique et sur ses beaux cheveux.

Mais, chaque jour au réveil, la méchante s'apercevait que la petite fille redevenait belle et propre. Elle décida alors de la surveiller la nuit. C'est ainsi qu'elle vit la vache s'extirper de l'écurie, venir jusqu'à sa fille, la nettoyer, lui changer ses vêtements et la caresser jusqu'à l'aube et puis, elle retournait à sa place.

Le cœur enflammé de courroux, la méchante femme appela son mari et lui dit: « Tu amènes la vache chez le boucher, vous l'égorgez, vous exhumez ses os et vous distribuez sa viande aux pauvres. »

Ainsi, et avant la tombée de la nuit, la vache n'était plus.

La marâtre continua à maltraiter la jeune fille, mais chaque nuit, une lune apparaissait dans le ciel, illuminait la fenêtre de la jolie fillette, et la maman quittait sa tombe en sa forme humaine pour soigner et consoler sa fille. 
Un jour, le sultan annonça qu'il donnait de grandes fêtes à l'occasion de son mariage et qu'il invitait tout le peuple. La sorcière habilla sa fille d'un beau caftan, des babouches dorées, d'une parure scintillante et l'emmena à la fête. Avant de sortir, elle jeta une grande poignée de cendre au visage d'Aïcha et lui fit prendre une charge de blé, une charge de millet et une charge de maïs qu'elle mélangea et lui dit : « Si tu ne me tries pas ces graines d'ici mon retour, tu seras amèrement punie.»

Dès que les deux méchantes eurent quitté la maison, la mère d'Aïcha Rmada apparut. Elle apportait un magnifique caftan tissé en or, chamarré de pierreries, avec un voile en soie, une parure et une ceinture ornée d'émeraudes vertes, lui enfila de jolies babouches brillantes et l'amena à la fête en laissant des petits oiseaux s'occuper de la tâche que lui avait conféré la méchante belle-mère. Tout le monde fut fasciné par sa beauté sans égale.

Avant la fin de la fête, la mère prit Aïcha dans ses bras et l'emporta à la maison. À ce moment, la fille perdit une de ses babouches. Les gardes la ramassèrent et la ramenèrent chez le roi qui, en la voyant si petite, jura : « je n'épouserai que celle à qui appartient cette babouche » et il délaissa aussitôt sa fiancée.

Le lendemain, le roi envoya des vieilles dans les quatre coins du royaume pour trouver le pied qui allait à la babouche. Elles arrivèrent à la maison d'Aïcha Rmada, la sorcière leur présenta le gros pied de sa fille mais, la babouche ne lui allait pas. Alors qu'elles s'apprêtèrent à sortir, le coq de la maison se mit à crier : «Cou, cou, cou, la propriétaire de la babouche est Aïcha Rmada. Elle est enfermée derrière les planches à la cuisine. » Elles enlevèrent les planches et retrouvèrent la belle Aïcha, resplendissante, vêtue de son beau caftan avec un pied nu et un autre dans la même babouche qu'elles tenaient dans leurs mains.

À sa vue, le roi perdit la raison, et l'épousa aussitôt. Ce jour-là, Aïcha décida de pardonner sa méchante marâtre et sa sœur et les accueillit dans le palais, mais ces deux sorcières n'oublièrent jamais leur haine à son égard. L'année suivante, le roi partit en guerre, laissant son épouse enceinte.

Un jour, la méchante fille demanda à sa sœur de lui montrer le puits où l'on puise l'eau du roi pour ses ablutions. Sans aucune méfiance, la jeune reine la conduisit à ce puits, elles se penchèrent pour regarder l'eau et la méchante poussa la reine et la fit tomber en bas. Elle retourna au palais, enfila les robes de la reine, mit un voile sur son visage et prétendit qu'elle ne l'enlèverait qu'au retour de son époux.

Le roi revint de la guerre, se précipita vers son épouse, et s'approcha d'elle pour la caresser et lui enlever le voile. Ayant peur d'être découverte, la méchante repoussa brutalement le roi. En colère, il se retira dans son pavillon et demanda à son servant d'aller au puits et de tirer l'eau pour ses ablutions. L'esclave arriva au puits, lança le seau mais une voix forte sécria : "Oh mécréant, tu veux donc tuer mon enfant ! L'esclave courut à toutes jambes, et raconta l'incident au roi. Alors, le roi alla lui-même au puits, lança le seau, et il reçut les mêmes injures que son esclave. Le roi interrogea la voix et dit : «Qui êtes-vous ? et que faites-vous dans le puits ? ». La voix répond : "Oh mon roi, je suis votre épouse Aïcha et je porte votre enfant que j'ai accouché dans le puits.» Le roi reconnu la voix de sa femme, appela ses gardes et la fit sortir du trou. 
Une fois entre les bras de son époux, la belle Aïcha lui raconta toute l'histoire de sa mère, changée en vache, puis tuée et comment sa sœur l'avait jetée, enceinte, dans le puits pour prendre sa place auprès de lui. Elle lui confessa que depuis ce jour, sa mère lui venait en secours ainsi qu'à son enfant. Le Roi dit à sa femme : "Quel châtiment veux-tu que j’inflige à ces femmes? ». La Reine répondit : «Je veux les punir moi-même. »

Elle décida de se faire passer pour la méchante sœur et de cacher son visage par le voile qu'elle portait. Elle appela sa marâtre et dit : «Ma mère, Aïcha va retourner ce soir au palais, j'aimerais que tu lui jettes un sort pour quelle devienne une vache et ainsi je pourrai prendre sa place.»Etonnée, la sorcière lui dit: « Mais qu'est-ce qu'elle a ta voix, elle ressemble à celle d'Aïcha. » La belle répondit : " Mais ma mère, je parle comme elle pour que le roi me croie. » La reine sourit et sortit de la chambre, en attendant que le soir vienne pour qu'elle exécute le vœu de sa fille.

À la tombée de la nuit, les gardes ligotèrent les mains de la méchante fille, lui mirent le voile et la mirent dans la chambre de la reine. La sorcière arriva, pressée, jeta le sort sur sa fille qu'elle prenait pour la belle Aïcha et la vit se transformer en vache. Aussitôt, la belle demanda aux gardes : "Vous ramenez cette vache chez le boucher, vous l'égorgez, vous brûlez ses os et vous distribuez sa viande aux pauvres. »

Quand la sorcière vit Aïcha, elle comprit qu'elle avait tué sa fille et mourut de rage dans l'heure.

Et ainsi, la belle Aïcha vécurent heureuse avec son époux et ils eurent quatre enfants beaux comme la lune.

\section{La fille de la lune:}

Il était une fois, un riche commerçant et son épouse qui eurent une petite fille aussi belle que la lune. Ils l'adoraient beaucoup. Elle était si douce et aimable que la lune se mettait à sa fenêtre chaque soir pour illuminer son petit visage angélique. Ainsi, les servantes de la maison l'appelaient La fille de la lune. Quatre ans après sa naissance, la maman décéda et laissa derrière elle le cœur brisé de son époux et de sa petite fille qui pleurait sans cesse. Chagrinée, la lune décida de ne plus la quitter.

Un jour, on proposa au commerçant d'avoir une nouvelle épouse, qui pourrait consoler sa petite fille et apporter de la joie à leur vie. Convaincu et pensant bien faire pour sa fille, il épousa, en deuxièmes noces, une femme hautaine et haïssable qui savait dissimuler sa méchanceté sous un visage souriant. Elle avait une fille qui lui ressemblait.

Aussitôt les noces célébrées, la belle-mère dévoila son vrai visage à la petite fillette. Elle commença par lui faire subir une méchanceté atroce. Peu de temps plus tard, et ne pouvant survivre à la perte de son épouse, le commerçant s'éteignit en laissant derrière lui La fille de la lune.

Les années passèrent et le rôle de la petite fillette devint celui d'une servante. Elle s'occupait de toutes les tâches viles de la maison. Elle rangeait la chambre de la méchante ainsi que celle de sa fille, lavait le linge sale, cherchait l'eau au puits. Le soir quand tout le monde se couchait, la petite fillette s'abritait dans la cuisine où la mé- 
chante l'avait condamnée à dormir. La lune venait la consoler, illuminer sa solitude et la surveiller jusqu'au lever du soleil.

Un jour, le roi lança un appel dans tout le royaume aux jeunes filles des grandes familles. Il allait organiser un bal pour choisir une épouse au prince. La méchante marâtre ainsi que sa vilaine fille passèrent des jours à se préparer et à choisir le costume de la soirée. Elle mit un beau caftan de couleur rouge pourpre et des babouches dorées. Sa mère la coiffa d'un voile en organza brillante en laissant apparaître ses mèches entremêlées. Mais elle était toujours laide et haïssable.

Avant de sortir, toute contente, la méchante dit à La fille de la lune : «Tu vas trier ces trois charges de blé, de maïs et de millet avant mon retour. Sinon, tu seras battue tous les jours. » Avant de partir, elle renversa de son pied les sacs de graines et les éparpilla dans les différents coins de la cuisine.

La fille de la lune suivit des yeux la méchante marâtre et sa fille par la fenêtre, habillées et coiffées, pour aller assister au bal du roi. Restée seule à la maison, elle éclata en sanglots, versant ainsi toutes les larmes de son corps. De la fenêtre, la lune qui la regardait attristée, laissa descendre une lumière brillante qui, en arrivant à côté de la fillette, lui effleura les joues. La belle leva les yeux et dit : « Mère !» La fée répondit « ayih a-bntī anā lmīma dīālk / oui ma fille, c'est moi, je suis venue essuyer tes larmes et pour te rassurer que je suis toujours là pour te réconforter.Je t'ai ramené un caftan brodé avec des fils de lumières, orné d'étoiles et de pierres du ciel. » En une seule caresse, elle changea sa fille en une princesse des mille et une nuits. Vêtue d'un somptueux caftan qui brillait de mille feux, de couleur verte, et d'une ceinture en or, incrustée de pierres. Ensuite, elle lui enfila de jolies babouches qui lui donnaient une allure de fée. Avant de quitter la maison, la fille embrassa les mains de sa mère pour avoir sa bénédiction / bāš tāhl rḍā.

La mère accompagna sa fille au bal du roi. À l'entrée, tous les invités furent éblouis par la beauté sans pareille de la jeune fille. En écoutant les chuchotements de la salle, le prince se précipita pour rencontrer celle qui avait charmé toute la foule. Mais comme il ne pouvait pas s'approcher d'elle, il attendit son départ pour la suivre jusqu'à la maison et rencontrer son père.

Une fois la lune réapparue dans le ciel, la maman emporta en un clin d'œil sa fille dans ses bras et l'emmena à la maison. En courant si vite, la belle fit tomber une babouche dans le corridor du palais. Le prince, coincé entre les invités, les vit s'éloigner dans le noir. Mais dans le corridor, quelque chose brillait de mille feux. Il s'approcha et ramassa une babouche que La fille de la lune avait fait tomber en courant.

Le prince était fort en peine, il déclara donc qu'il ne goûterait aucune nourriture ni fermerait l'œil si on ne lui trouvait pas la propriétaire de la babouche. Le roi envoya ses serviteurs dans les quatre coins du royaume pour trouver celle à qui la babouche appartenait. On commença donc à la faire essayer à toutes les filles de grandes familles. Enfin, on la ramena chez la méchante marâtre et sa fille qui fit tout son possible pour la porter. Mais elle ne put en venir à bout. Alors, La fille de la lune apparut au fond du salon et leur demanda si elle pouvait essayer la babouche. La méchante marâtre, voulant la chasser, fut interrompue par les servantes du Roi : «Oui bien sûr, 
le roi nous a ordonné de la faire essayer à toutes les filles du royaume.» Une fois son pied dedans, la babouche s'enfila facilement sans peine. Sous le regard abasourdi des deux méchantes, les servantes invitèrent La fille de la lune à les suivre au palais. Mais elle les pria de la laisser jusqu'au soir, elle voulait que la lune en soit témoin.

Les servantes attendirent sagement dans la maison de la jolie fille, pendant que les deux méchantes la suppliaient amèrement pour quelle leur pardonne leur atrocité à son égard.

Quand la lune fut là, sa maman réapparut en sa forme humaine, dans toute sa splendeur, et elle lui caressa le visage. Elle la bénit et l'accompagna à la demeure de son futur époux, tandis que les deux méchantes restèrent seules et humiliées dans leur maison.

Le roi donna des fêtes dans tout le royaume pour célébrer l'union de son fils et de sa dulcinée et ils se promirent de vivre heureux jusqu'à ce que la mort ne les sépare.

\section{La création d'un conte hybride où les imaginaires marocain et français se rencontrent}

Marion Sauvaire explique que la notion d'hybridité culturelle signifie la naissance d'une nouvelle culture suite à la rencontre de deux cultures différentes : " la notion d'hybridité aille à l'encontre d'un discours fantasmatique sur l'unité de l'identité originelle, il demeure que l'hybridité, comme le métissage, reproduisent une logique dualiste, qui de deux identités en créent une nouvelle. » (Sauvaire, 2012)

À cet effet, la présentation d'un conte sur une scène de migration par un conteur populaire marocain nécessite d'avoir recours à des symboles reconnaissables par ce nouveau public. Cependant, cela n'implique pas la suppression des traits de sa propre identité.

Aïcha Rmada est la version marocaine de Cendrillon en France, Cinderella aux États-Unis, Yexian en Asie, Aschenputtel en Allemagne, Cenicienta en Espagne et les énumérations restent longues.

Il s'agit d'un conte universel qui garde le même noyau central à savoir, une belle fille maltraitée par sa marâtre, qui va épouser un prince. Par ailleurs, les variations de chaque version sont la conséquence des différences qui existent entre les imaginaires collectifs des différents pays et cultures du monde. À l'instar des différentes composantes de la littérature orale, à savoir le chant, les devinettes, les mythes et bien d'autres, le conte est également un transmetteur des coutumes, des croyances et des traditions vernaculaires. D'ailleurs, Riadh Ben Rejeb confirme que le conte est «le reflet, l'ombre, l'image de la réalité sociale, dont il est partie intégrante. » (Ben Rejeb, 1994, p. 219) 
La version traditionnelle Ä̈cha Rmada a été recueillie sur la place Jamaa elFna à Marrakech alors que la version revisitée La fille de la lune a été présentée dans le cadre d'un festival en France. Dans ces deux versions, les personnages principaux sont des jeunes filles, mais chacune représente une culture particulière. Aïcha porte l'identité marocaine, alors que La fille de la lune est une figure qui a été conçue pour représenter les deux cultures à la fois, française et marocaine.

La différence entre ces deux personnages féminins se manifeste d'abord dans le choix des noms qui leurs ont été attribués et qui s'est effectué en fonction du contexte de narration. Dans le conte populaire qui a été présenté au Maroc, la petite fille s'appelle Aïcha. Littéralement, ce prénom signifie en arabe «vivante », il est dérivé

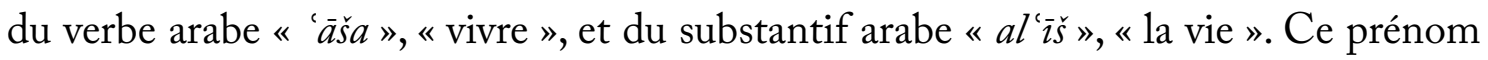
est l'un des plus populaires au Maroc. Il porte une forte symbolique religieuse puisqu'il fait référence à la troisième épouse du prophète Mohammed que Malek Chebel présente ainsi : «elle était la fille d'Abou-Bakr, 'litt., le Père de la Vierge', premier des quatre Khalifes et épouse préférée du prophète ». (Chebel, 1995, p. 23)

Dans le même sens Sobhi Bouderbala postule :

C'est bien Aïcha, toutefois, qui reste la plus célèbre des épouses du Prophète. Fille de son plus fidèle lieutenant et futur premier calife Abu Bakr, elle est élevée par la Tradition à un rang inégalé parmi les mères des croyants. Épouse préférée de Muhammad et seule vierge qu'il ait épousée (d'où le surnom d'Abu Bakr, père de la vierge, Aïcha est aussi l'une des principales autorités en matière de hadith. (Bouderbala, 2019, p. 34)

Ces deux citations mettent en exergue la valeur que porte le prénom Aïcha dans le référent religieux, et qui prend toute son ampleur dans les sociétés arabo-musulmanes en général, et en particulier marocaines. Certaines familles marocaines se réfèrent aux différents noms du prophète, à ses qualificatifs, ou aux prénoms des membres de sa famille, pour baptiser leurs enfants en prétendant qu'ils auront les mêmes traits de caractère ou qu'ils représenteront les mêmes valeurs que ceux qui les portaient. Dans ce sens, Néfissa Geoffroy et Younès Geoffroy confirment :

Dans ce cas, ce n'est pas tant la signification de ces prénoms qui est prise en compte que les qualités qui furent manifestées par ces personnalités. Celles-ci incarnent pour le musulman les valeurs islamiques et sont comme des bannières derrière lesquelles il aime à se ranger. (Geoffroy, 2000, p. 34)

Si nous nous appuyons sur ce témoignage, nous pouvons déduire qu'Aïcha a hérité de tous les traits de caractère de l'épouse favorite du prophète Mohammed. Elle est non seulement une jeune fille brave, qui survivra à toutes les épreuves difficiles que lui inflige sa marâtre, mais elle est aussi chaste et pieuse. De cette manière, le conteur 
parvient à susciter la compassion du public avec un personnage qui porte le même nom que celui de l'épouse favorite du prophète Mohammed et qui subit la cruauté de sa marâtre. En effet, dans les sociétés musulmanes, les prénoms issus du référent religieux sont à l'origine de l'union communautaire.

Pour éclairer davantage le sens de nos propos, nous citons Y et N. Geoffroy qui expliquent :

L'éclosion d'une véritable fraternité entre croyants ainsi que la diffusion d'un esprit communautaire ne pouvaient avoir lieu sans réformer certains traits de société peu conformes à l'idéal islamique. En changeant les prénoms laids, le prophète cherchait à redresser les mœurs de son peuple. (Geoffroy, 2000, p. 25)

Le conteur sort de son cercle familier où il partageait avec ses confrères les mêmes codes, les mêmes symboles, mais aussi la même langue pour s'installer dans un pays d'accueil où il doit créer un espace d'échange dans lequel deux cultures devront fusionner. Dans ce cas de figure, le conte doit porter la marque d'une influence interculturelle. Conscient que chaque nom a une charge culturelle, le conteur a choisi de substituer le nom La fille de la lune à Aïcha. L'importance de cette démarche peut être justifiée par les propos de Rita El Khayat:

Du point de vue anthropologique, le prénom correspond à quelque chose de très profond dans la culture considérée. Il tient à la langue de l'ethnie ou du groupement des peuples considérés, à son histoire, à ses références, à sa religion et à ses croyances, à son évolution, à son sens du symbole et de la trace. (E1 Khayat, 2001, p. 66)

Il paraît que le choix de ce nom répond à l'objectif du conteur, c'est-à-dire, créer un conte hybride où seront réunies sa culture originelle ainsi que celle de son public.

La lune est un symbole auquel les deux cultures attribuent une grande importance. Les arabes en général, et en particulier les marocains, «trouvent la nuit, quand apparaît la lune, apaisante et douce, propice au voyage et aux aventures qui prouvent la bravoure des hommes. » (Chevalier et Gheerbrant, 1982, p. 592). Dans la culture française, l'apparition de la lune, la nuit, est assimilée à la beauté parfaite qui illumine les ténèbres, comme en témoignent Jean Chevalier et Alain Gheerbrant : « La lune, astre des nuits, évoque métaphoriquement la beauté et aussi la lumière, dans l'immensité ténébreuse. » (Chevalier et Gheerbrant, 1982, p. 590)

Aïcha et La fille de la lune ont perdu leurs mamans à un âge précoce. Cellesci sont réapparues plus tard dans le récit sous des formes différentes. Dans la version traditionnelle, la mère s'est métamorphosée en vache alors que dans la version revisitée elle a pris la forme de la lune. À première vue, nous pensons que ces deux formes sont 
loin d'être semblables. Néanmoins, l'analyse de la symbolique de la lune, évoquée dans la version revisitée du conte, dévoile un rapprochement de sens avec le symbole de la vache qui a été cité dans le conte populaire.

Dans le Dictionnaire des symboles, emblèmes et attributs, la lune est définie comme suit : «Lune : Astre. Elle représente l'enfance. Animaux : Vache» (Pillard,1897,p.109). Dans le même sens, Clément Bovin confirme : «La vache était le symbole de la Lune, le taureau celui du Soleil, le fécondateur.» (Bovin, 2005, p. 139)

De ce fait, nous remarquons que parfois, certains éléments peuvent avoir le même sens dans deux cultures mais qu'ils se manifestent sous des formes différentes. De cette manière, la réalisation d'une «interaction interculturelle positive » (Shan, 2004) dépend en partie de la capacité de l'individu à retrouver l'équivalent des mots, des symboles, ou des gestes qui sont utilisés dans la culture de son interlocuteur.

Dans son pays d'origine, le conteur peut s'aventurer à décrire des scènes atroces ou cruelles sans craindre le rejet alors que dans un contexte interculturel, il doit s'autocensurer préventivement pour éviter de heurter la sensibilité du public qui l'écoute. Le passage de la mère transformée en vache, égorgée et distribuée aux pauvres ainsi que celui de sa résurrection la nuit pour consoler sa fille, a été remplacé, dans le conte revisité, par le décès naturel de la maman, qui a habité la lune et qui est descendue consoler et habiller sa fille sous la forme d'une belle lumière, en provenance du ciel.

Pour respecter les règles de la bienséance, le conteur s'est abstenu de décrire une image bouleversante qui porte atteinte à la femme et à l'humanité et qui risque de choquer le public, composé d'adultes, mais aussi d'enfants. Il est conscient de son rôle de médiateur culturel dans un pays d'accueil. De ce fait, il refuse de transmettre, à travers ses contes, une image qui est susceptible de nuire à son identité.

Certains traits de la culture marocaine apparaissent implicitement dans le conte La fille de la lune. La rencontre entre le prince et sa bien-aimée est entravée par les invités du bal qui représentent l'ancienne société marocaine conservatrice. Ce système social condamne toute forme d'union entre un homme et une femme avant les noces. D'ailleurs, le conteur exprime cette idée verbalement en disant: «Mais comme il ne pouvait pas s'approcher d'elle, il attendit son départ pour la suivre jusqu'à la maison et rencontrer son père ${ }^{3}$."

Il convient de rappeler que la figure paternelle est, dans la société traditionnelle, le tuteur de la fille, le seul détenteur du droit de décision. C'est un constat

\footnotetext{
3 Extrait du conte La fille de la lune.
} 
qui a été relevé également par El Hassan Yacoubi: "L'enfant/individu et la mère/ femme sont des sujets qui doivent le respect total au père/mari/chef.» (Yacoubi, 2008, pp. 315-347)

La notion d'hybridité culturelle est évoquée dans cette scène. D'une manière biaisée, le conteur insère, dans le conte revisité, une idée qui sera perçue comme désuète dans un contexte où la femme s'est affranchie de l'autorité patriarcale.

La fille de la Lune est censé être un conte adapté purement à la culture et à l'imaginaire français. Néanmoins, le conteur ne s'est pas abstenu d'y insérer certains traits phares de la culture marocaine. S'il décrit le caftan vert que porte la jeune fille comme un objet céleste qui charme les regards, c'est parce que le vert est une couleur emblématique en Islam. Malek Chebel en explicite les différentes valeurs :

Symbole de l'Islam et des dignitaires musulmans. Couleur de l'Islam, du Paradis musulman, la couleur verte est, de plus, la couleur privilégiée du prophète Mohamed et de ses Compagnons. De là, d'ailleurs, provient son caractère sacré. Ses supports sont variés : vêtements d'apparat, reliures du Livre saint, étendard des armées islamiques. Sa place en Islam est si sacrée que les musulmans rigoristes refusent de la faire apparaître sur les tapis, car la fouler aux pieds est considéré comme une atteinte à la dignité de l'Islam. Il symbolise le paradis, la longévité et l'immortalité. D'ailleurs, les édifices et les mausolées, dans les pays musulmans, sont peints de couleur verte puisqu'ils représentent dans la croyance populaire, les lieux des âmes immortelles. (Chebel, 1995, p. 123)

Outre sa valeur religieuse, le caftan vert a également une importance culturelle au Maroc. C'est un costume que les jeunes mariées marocaines portent le jour du henné en symbole de fertilité, de jeunesse, de bonne santé et de longue vie.

La prise en considération de la structure sociale de la France a fait que le conteur a changé dans le conte revisité la mention de la bigamie, qui figure dans la version traditionnelle, par l'idée des deuxièmes noces. La structure de la famille traditionnelle est remplacée par l'autre modèle contemporain de la cellule familiale.

Nous relevons également que dans le conte décontextualisé, le merveilleux est soumis à une certaine rationalité. La fée apparaît brièvement et se transforme aussitôt en la mère de la petite fille. Dans ce passage, le conteur identifie la figure maternelle à un être légendaire, beau et idyllique. Cette scène émouvante est un moment crucial dans la performance du conteur. À défaut de partager avec son public les mêmes codes, il crée un moment d'échange émotionnel. Indubitablement, l'échange reste le pilier de la réussite d'une performance orale.

Pour répondre aux exigences du contexte interculturel, le conteur a eu recours à certaines figures qui ont des sens presque similaires dans les deux cultures. Il a dû 
également remplacer certains symboles propres à sa culture maternelle par d'autres qui ont été puisés dans le référent culturel du pays d'accueil. Cette démarche a pour objectif de favoriser la communication interculturelle et, par conséquent, de transmettre le récit et de captiver l'attention du public.

Les contraintes rencontrées par le conteur, lors de la production d'un conte revisité pour le présenter dans un pays d'accueil, ne sont pas synonymes d'handicap. Elles sont plutôt synonyme d'apanage de l'échange interculturel, qui exige impérativement la création d'un nouveau code de communication, métissant deux cultures. Tout comme le texte, la performance orale a également subi des modifications en vue de s'adapter aux codes non verbaux de la société française.

\section{L'adaptation de la performance à un nouveau contexte socio-culturel}

Nous avons expliqué plus haut que La fille de la lune est l'adaptation du conte traditionnel Aïcha Rmada. Ladite adaptation répond non seulement à des exigences culturelles et linguistiques propres au pays d'accueil, mais aussi aux directives des organisateurs du festival et des metteurs en scène.

Afin de mettre au clair ce dernier aspect, nous proposons une comparaison entre le contexte traditionnel où le conteur jouait sa performance et la scène du festival du conte en France. Cette comparaison nous permettra de comprendre les modifications qui ont été apportées à la forme de présentation du conte réécrit en vue de le présenter dans un contexte interculturel.

Aïcha Rmada a été recueilli sur la place Jamaa el-Fna à Marrakech un soir d'été. Dans ces circonstances, le conteur sait au préalable que le public qui rejoint le cercle halqa $a^{4}$ est disposé à l'écouter jusqu'à la fin de sa performance. Il s'agit d'une activité qui a du succès en été. Lorsque la température est très élevée à Marrakech, les habitants de la ville, ainsi que les touristes, peuplent les places publiques pendant toute la nuit.

Or, la version intitulée La fille de la lune a été présentée dans le cadre d'un festival en France où le conteur ne disposait pour son passage, que de quelques minutes. De ce fait, une réécriture plus réduite s'est imposée. Cela apparaît au niveau de la différence de durée des deux performances orales : la narration d'Ä̈cha Rmada s'est étalée sur 15 minutes et 9 secondes alors que celle de La fille de la lune a pris fin au bout de 7 minutes et 18 secondes.

4 Regroupement circulaire du public autour d'un interprète dans une place publique, un marché ou à la porte de la ville. 
Pour réécrire une nouvelle version du récit, le conteur a certainement pris en considération le temps limité qui lui a été accordé pour son passage. C'est ainsi qu'il a procédé pour résumer le texte et le simplifier pour n’en garder que les faits majeurs.

Outre la taille du conte, la performance orale du conteur a également été influencée par le contexte interculturel. Avant d'élucider ce constat, nous proposons d'abord une définition de la notion de la performance. Selon Dell Hymes, « la performance orale est l'ensemble des compétences communicationnelles qui sont analysées par les chercheurs et qui leurs permettent d'étudier les interactions humaines et sociales propres à une communauté donnée »(Hymes, 2015, p. 5). En effet, cette notion englobe l'ensemble des pratiques artistiques, des rituels de comportements, des manières de parler, des gestes et des mouvements qui représentent les identités individuelles et collectives.

À la lumière de ces précisions, nous allons relever les signes de l'adaptation de la performance du conteur à la scène du festival. Nous commencerons d'abord par étudier la différence entre l'arrivée sur scène du conteur à la place publique Jamaa elFna et son entrée en scène sur les estrades du festival en France.

Dans les places publiques, le conteur est d'abord un inconnu, il arrive sur les lieux, choisit un endroit au milieu de la place et s'éloigne de toutes les sources de vacarme afin de commencer son activité. Il fait des mouvements circulaires qui lui permettent de regarder les différents coins de l'espace et de cibler tous les passants : le but est d'inviter le public à voir sa performance. Les mouvements rotatifs miment la nature du spectacle, la halqa, qui regroupe un public en forme circulaire pour lui présenter un récit.

La place publique est un espace vaste, illimité, dans lequel le conteur veut créer une plateforme d'échange avec un public inconnu. Cet espace est vide de décor ou d'indices qui se rapportent à l'art ou au spectacle. Le conteur doit le meubler pleinement par son corps et par ses mots.

Avec sa main droite, le conteur invite les passants en leur montrant le lieu de la performance. Il s'agit d'un geste de bienvenue qui trouve son origine dans le code de l'hospitalité marocaine et qui consiste à tendre la main ouverte vers son invité et à la retirer pour lui montrer le lieu où il peut s'installer. Le conteur considère que le cercle qu'il prépare pour son conte est un « chez lui » où il doit bien recevoir ses invités (le public).

Dans cet espace nu, ces mouvements déclarent un double commencement : la naissance de la performance et celle de l'espace dans lequel elle va se dérouler. Avant d'entamer le récit, le conteur laisse le temps à son corps de transmettre le caractère ma- 
gique du spectacle. Les mouvements lents et le regard sage lancent les prémices d'une rencontre sereine. Dans ce cas, le spectateur réalise qu'il ne doit pas rester passif, mais qu'il doit plutôt contribuer à faire exister le spectacle par des rétroactions signifiantes qui confirment son implication dans l'échange.

Pour leur part, certains adhérents du cercle manifestent leur présence par la main levée en guise de salutation et de remerciements ou par des sourires timides, tout en s'approchant du conteur. D'autres rejoignent le cercle et se recroquevillent, la main sous le menton, pour manifester leur disposition à assister à la narration du conte. Le conteur traditionnel est donc à la fois un metteur en scène et un interprète. L'aménagement de l'espace, la présence de l'auditoire et la présentation du conte ne dépendent que de lui.

Contrairement à cela, dans le festival du conte, le public est invité à voir et à écouter la performance. Il doit s'installer avant l'arrivée du conteur afin de l'accueillir. Cette permutation des rôles, en comparaison avec le déroulement de la performance dans les cercles traditionnels du conte fait que l'entrée en scène du conteur doit être programmée et non pas improvisée. Il suit les indications d'un metteur en scène qui lui montre les étapes de son apparition sur scène afin d'attirer l'ensemble de l'auditoire.

Le conteur apparaît, après le lever du rideau, la main droite en l'air pour saluer les présents, et s'appuie avec la main gauche sur sa canne. Il avance vers le public pour réduire les distances qui les séparent et pour répondre à sa curiosité, lui qui s’interroge sur l'être et le paraître de cet étranger. Dans ce bref moment qui précède la prise de parole, les gestes permettent au conteur d'embrasser l'espace et de s'impliquer avec son auditoire, malgré les contraintes architecturales et culturelles du lieu de la performance.

Par les mouvements du corps, le conteur crée trois dimensions différentes dans l'espace horizontal qui l'expose aux spectateurs. Pour ce faire, il tire trois révérences à la salle : il commence par le milieu, se déplace vers l'extrémité droite et puis vers l'extrémité gauche de l'estrade. Le choix du costume est également un élément de la performance qui favorise la réception du conte. Il s'agit d'un élément visuel important à la création d'une atmosphère merveilleuse.

Lors de la présentation du conte Ä̈cha Rmada sur la place Jamaa el-Fna, le conteur s'est présenté en portant une tenue moderne composée d'un pantalon, d'une chemise, d'une veste et les cheveux blancs serrés ne laissant échapper aucune mèche. Le contexte lui permettait, sans contrainte, de se libérer du costume traditionnel connu de tous. La magie du conte, seule, pourrait créer une veillée réussie. 
En France, le conteur change de costume et arrive avec un burnous ${ }^{5}$ et une gandoura blancs ${ }^{6}$, un turban et des babouches jaunes. Dans le patrimoine populaire marocain, le burnous de couleur blanche a toujours été porté lors des événements religieux. Ce vêtement est porté également par les prédicateurs des mosquées, chaque vendredi, comme un symbole de pureté, de crédibilité et surtout de suprématie de la parole qu'ils prêchent. Il est également connu que le burnous est un accessoire qui était porté par les grandes personnalités du pays et par les sultans également. Le turban a été, dans le passé, la coiffe des dignitaires du pays. C'était un signe de pouvoir et de richesse. Seuls les descendants des familles nobles ornementaient leurs têtes par cet accessoire.

Ce costume ostentatoire décrit préalablement accorde au conteur la légitimité de transmettre un récit oral qui est issu de la mémoire collective marocaine, dans un pays d'accueil. Le public se représente mentalement la subtilité culturelle de ce costume et admet que le conteur, provenant d'un pays étranger, mérite une attention particulière.

Au bout de cette analyse, nous constatons que la performance orale présentée dans un pays d'accueil fait également l'objet de plusieurs modifications en vue de s'adapter au contexte culturel, au public et aussi à l'espace. Nous remarquons que malgré les contraintes architecturales de la scène du festival, le conteur a essayé de réduire les distances avec son public et de s'en approcher afin de créer un espace d'échange qui ressemble plus au moins à un cercle de conte traditionnel.

Cependant, le processus de réécriture d'un conte populaire propre à une culture donnée ainsi que sa transposition dans un contexte interculturel, ne sont pas des plus anodins. Généralement, des contraintes linguistiques et sémantiques s'imposent.

\section{Les contraintes linguistiques et sémantiques qui entravent la transmis- sion du conte revisité dans un contexte interculturel}

Comme tous les artistes, le conteur se prépare avant de monter sur scène et avant de rencontrer le public. Il s'agit d'écrire ou de réécrire le conte, de préparer une mise en scène et de visualiser mentalement le conte en lui donnant forme. Pour ce faire, il choisit un code de communication compréhensible par le public, afin de favoriser à la fois la transmission du sens et des images.

\footnotetext{
5 Grand manteau de laine à capuchon et sans manches, en usage dans les pays du Maghreb.

6 Tunique sans manches, qui se porte en Afrique du Nord sous le burnous.
} 
D'emblée, le conteur a hésité entre une performance en langue arabe, durant laquelle il va accompagner les mots par des gestes, et une performance en langue française qui lui demandera un travail colossal sur le choix des mots, la modification du conte, des symboles et des figures de style mais aussi sur le ton et le timbre de sa voix.

Louverture du conte s'est faite en arabe pendant les trois premières minutes durant lesquelles le conteur a remarqué que la majorité des spectateurs se sont penchés vers l'avant afin de lire ses gestes pour déchiffrer le sens de l'histoire. Par cette introduction, le conteur souhaitait uniquement attirer l'attention du nouveau public et susciter sa curiosité à l'égard de sa culture et de son identité.

À la quatrième minute, le conteur a introduit le conte en français par la formule classique « il était une fois ! » connue de tous, sans jamais changer de ton ni de timbre de voix. À ce moment, le public fut rassuré et s'est mis à écouter pour recevoir le conte dans sa langue maternelle.

Dans les cercles de contes traditionnels au Maroc, halqa, le conteur s'attarde sur la description prolongée de certains passages, de certaines actions ou de certains personnages au point de leur donner une forme dans l'imaginaire de l'auditoire. Cependant, dans un pays d'accueil, les contraintes de la langue s'imposent. Nous remarquons que le conte est composé de phrases courtes, de brèves descriptions et presque d'une absence d'énumération. Il en résulte un conte écourté par rapport à celui qui a été narré dans son contexte d'origine.

Nous relevons également que dans le conte réécrit, certains passages sont transmis dans la langue maternelle du conteur, à savoir l'arabe, suivi d'une traduction en langue française. Dans ce cas, le conteur a jugé de l'incapacité de la traduction à transmettre fidèlement la connotation véritable de certaines images. Dans le passage qui décrit la scène de la rencontre entre la fille et sa mère, extrait du conte revisité, le conteur commence d'abord par prononcer la réplique en arabe avant de la traduire en français. «ayih $a-b n t i \bar{~}$ anà lmìma dīalk». «Oui ma fille c'est moi ! ». Dans ce cas, la réplique dite en arabe a une portée émotionnelle que la phrase en français n'arrive pas à reproduire. Le mot « ayih » interprète sémantiquement un soupir, une détresse et une avidité aux retrouvailles ${ }^{7}$.

Dans ce contexte, la traduction reste incapable de transcrire certains symboles ou réalités culturelles. C'est le cas également du mot l-mìma, qui, en arabe dialectal marocain, abrège une longue description. Il signifie une maman, aimante, gentille, bienveillante et douce. En effet, c'est l'idéal de la figure maternelle. Or le mot «mère »si-

7 Ayih est un mot en arabe dialectal marocain (darija) qui peut être prononcé oralement en français ainsi: «eh ouiiiiii». 
gnifie, selon le Dictionnaire Larousse : « femme qui a mis au monde ou qui a adopté un ou plusieurs enfants ». La comparaison de ces deux expressions nous confirme, comme le pense Abdelouahed Allouche, l'incapacité des conteurs provenant de pays étrangers, à transmettre fidèlement certaines images mentales propres à leurs cultures, dans des pays d'accueil :

L'influence de l'imaginaire de la culture d'accueil dicte au conteur un texte désarticulé, au confluent des deux cultures mais impuissant à les marier harmonieusement. À ce stade de son évolution, le conte produit dans l'immigration reste en deçà du conte métis. (Allouche, 1993, p. 28)

Dans un contexte interculturel, tout comme les mots, les gestes doivent être interprétés parce qu'ils reflètent également une symbolique culturelle et identitaire. La fin de la scène qui décrit les préparatifs de la jeune fille pour se rendre au bal a été clôturée par la phrase : « la fille a embrassé les mains de sa mère pour avoir sa bénédiction : 'bāš tāb $\underline{d} d r d \vec{a}^{\mathbf{8}}$." "

Nous remarquons alors que la description a été faite d'abord en langue française pour ensuite insérer une traduction en arabe dialectal marocain (qui d'ailleurs n'a pas été comprise par la majorité du public).

L'insertion de cette mention en arabe émane de la nécessité de lier le geste à sa symbolique culturelle d'origine. Il existe une subtilité de sens entre le mot bénédiction et $r d . \bar{a}$. Dans le Dictionnaire des symboles, Chevalier et Gheerbrant précisent que le mot « bénédiction » signifie dans un contexte occidental « un transfert de forces. Bénir veut dire en réalité sanctifier, faire saint par la parole, c'est à dire rapprocher du saint qui constitue la forme la plus élevée de l'énergie cosmique. » (Chevalier et Gheerbrant, 1982, p. 592)

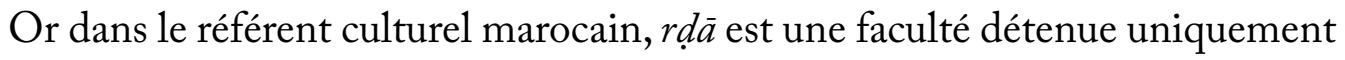
par les parents, les grands-parents ou bien les personnes âgées. Avant d'entamer un ouvrage, les enfants embrassent la main de leurs géniteurs pour obtenir leurs bénédictions qui a le pouvoir de les préserver de tous les aléas de la vie. Cette conviction a été tirée de la religion musulmane qui atteste, par des versets coraniques, que les parents sont des sujets sacrés auxquels les enfants doivent une entière obéissance.

La réécrire d'une nouvelle version du conte qui sera présentée dans un contexte interculturel, nécessite la maitrise de la langue, des codes et des symboles qui nourrissent la culture cible. La traduction littérale de la langue maternelle à la langue du

8 Ce passage est extrait du conte La fille de la lune. 
pays d'accueil reste incapable de transmettre les différentes connotations des mots et risque par conséquent d'entraver la compréhension du récit. Cela peut même installer des malentendus.

\section{Conclusion}

Le conte est incontestablement un médiateur de culture et d'identité. Mais il subit dans un contexte déraciné des modifications au niveau du contenu et de la forme. Ces modifications sont nécessaires pour la création d'une nouvelle version où deux cultures se rencontrent par le biais des symboles et des traits qui leurs sont propres.

L'intérêt de chaque performance orale est de persuader le public, de le captiver et de le divertir. En l'occurrence, la réalisation de ces objectifs dépend essentiellement de la capacité du public à déchiffrer et à comprendre les codes et les composantes du récit.

C'est pour cette raison que le conteur doit être en mesure de produire un conte revisité qui s'inspire des représentations sociales, du référent culturel et des traits identitaires du pays d'accueil. Cependant, nous avons remarqué que La fille de la lune qui a fait l'objet d'une analyse dans le cadre de cet article, porte non seulement des traits propres à la culture française mais aussi des passages qui évoquent le vécu et la culture marocaine. Cette version représente les traits de l'hybridité culturelle issue de la rencontre des cultures du monde malgré leurs différences.

Dans ce contexte, la performance orale a également été retravaillée afin de satisfaire les recommandations des organisateurs du festival. Cela manifeste la différence entre une séance de conte libre, animée dans les places publiques et celle qui est programmée sur une scène de spectacle.

Dans le cadre de cette analyse, nous avons remarqué que dans certains passages, le conteur fut incapable de se défaire catégoriquement d'un système de valeur et de représentation qu'il a développé au fil des années. Malgré l'effort fourni de sa part pour embrasser cette diversité culturelle, des contraintes linguistiques et sémantiques se sont imposées lors de la réécriture du conte. Le conteur, qui s'est habitué à conter en arabe parmi ses compatriotes, trouve dans ce contexte interculturel des difficultés à transmettre les connotations subtiles de certains passages qui évoquent des structures sociales, des valeurs morales ou des aspects culturels propres à son pays.

C'est pour cette raison qu'on ne peut pas considérer que La fille de la lune est un conte français mais que c'est plutôt un conte marocain revisité et adapté à l'imaginaire français. 


\section{RÉFÉRENCES BIBLIOGRAPHIQUE}

Allouche, A. (1993). Les métamorphoses d'un conte maghrébin dans l'immigration. Hommes et Migrations (1161), 25-28. https://doi.org/10.3406/homig.1993.1952

Amahan, A. (1996). Le costume traditionnel. In M. Sijelmassi, A. Khatibi, \& E.-H. El-Moujahid (dirs.), Civilisation marocaine: arts et cultures (pp. 212-219). Éd. Oum.

Ben Rejeb, R. (1994). La culture au Maghreb sa transmission à travers contes et prénoms. Ibla, 57(1994), 219-240.

Bouderbala, S. (2019). Le Prophète et ses femmes. L'Histoire (458), 32-57. https://wwww.lhistoire. $\mathrm{fr} / \mathrm{le}$-proph\%C3\%A8te-et-ses-femmes

Bovin, C. (2005). Taureaux, vaches sacrées, vaches folles : de la prébistoire à la corrida. Le Plein Des Sens.

Chebel, M. (1995). Dictionnaire des symboles musulmans. Albin Michel.

Chevalier, J. \& Gheerbrant, A. (1982) Dictionnaire Des Symboles Mythes, Rêves, Coutumes, Gestes, Formes, Figures, Couleurs, Nombres. Robert Laffont et Jupiter.

Clanet, C. (1993). L'interculturel, introduction aux approches interculturelles en éducation et sciences bumaines. Presses Universitaires du Mirail.

Dasen, P. R. \& Retschitzki, J. (1989). Recherches interculturelles:Une association, un colloque. In C. Clanet (Éd.), Socialisations et cultures (pp. 9-16). Presses Universitaires du Mirail.

Geoffroy, Y et Geoffroy, N. (2000). Le livre des prénoms arabes. Al-Bouraq.

Hutnyk, J. (2005). Hybridity. Ethnic and racial studies. 28(1), 79-102. https://doi.org/10.1080/ 0141987042000280021

Hymes, D. (2015). Breakthrough into performance. Guaraldi.

Kapchan, D. A. (2017), Performance : réénonciation et réincarnation dans les genres de la performance. Cabiers de littérature orale (82), 20-43. https://journals.openedition.org/clo/4159

Pillard, M. (1897). Dictionnaire des symboles, emblèmes et attributs. Henri Laurens.

Roland, H \& Vanasten, S. (Éds.) (2010). Les nouvelles voies du comparatisme. Academia Press.

Sauvaire, M. (2012) Hybridité et diversité culturelle du sujet:des notions pertinentes pour former des sujets lecteurs? Littera-Incognita (4). https://blogs.univ-tlse2.fr/littera-incognita-2/ 2016/02/16/numero-4-2011-article-3-ms

Shan, B. (2004), La communication interculturelle: ses fondements, les obstacles à son développement. Communication et organisation, 24. https://doi.org/10.4000/ communicationorganisation.2928

Yacoubi, E. (2008). L'écriture de soi comme modèle de contestation et d'affirmation de l'individu dans la société marocaine. Chimères, 1(1-2), 315-347. https://doi.org/10.3917/chime.066.0315

Farah Abdelali. Doctorante à l'Université Hassan II de Casablanca, Faculté des Lettres et des Sciences Humaines Ben M'sik, au Laboratoire de recherches Langues, Littératures et Communication. Son sujet de thèse porte sur l'étude des procédés de détournement des contes populaires marocains de la réécriture à l'interprétation, sous la direction de Nadia Ouachene. Elle est également ancienne élève de L'ENS de Meknès, cycle de préparation à l'agrégation et professeur vacataire des techniques de communication.

Dernière publication : Abdelali, F. (2019). La performance orale du conteur traditionnel marocain. In N. Ouachene et L. Ouasmi, L'oralité de la production à l'interprétation (pp. 229-239). L’Harmattan. 